\title{
The Behaviour of Remolded Batu Pahat Soft Clay with Different OCR Values under Cyclic Loading
}

\author{
Alvin John Lim Meng Siang ${ }^{1, *}$, and Muhammad Arif Azraei Izzudini ${ }^{1}$ \\ ${ }^{1}$ Faculty of Civil and Environmental Engineering, Universiti Tun Hussein Onn Malaysia, 86400 Parit \\ Raja, Johor, Malaysia
}

\begin{abstract}
The Batu Pahat Soft Clay, (BPSC) of Universiti Tun Hussein Onn Malaysia, (UTHM) were low in shear strength, bearing capacity, and suffer large settlements when subjected to loading. They undergo varies of dynamic cyclic loadings during their design lifetime and the response was typically more complex, requiring engineers to investigate the dynamic behaviour of soils thoroughly in the laboratory. The objectives of this research were to simulate remolded Batu Pahat Soft Clay (RBPSC) samples with different $\sigma_{v}$, to study the dynamic shear modulus, $G$ and damping ratio, $\mathrm{D}$ of (RBPSC) under cyclic loading with different $\mathrm{f}$, OCRs, $\sigma_{\mathrm{v}}$, and $\sigma_{\mathrm{c}}$, and to analyses the correlation between G and D of the (RBPSC) with the OCR values under cyclic loading. As result, the $100 \times 50 \mathrm{~mm}$ of remoulded samples are succeed simulated by using large strain consolidation apparatus of 50,80 and $100 \mathrm{kPa}$ of pre consolidation stress, contain moisture ranging within 42 to $55 \%$. The series of remolded consolidated undrained dynamic cyclic triaxial test were ran under OCR of 1, 2, 3.85 and 4. Hence, it could be concluded that the $\mathrm{G}$ decreased when increasing of $f$ and OCRs subjected to increasing axial strain while the $G$ corresponding to each $\sigma_{\mathrm{v}}$, increases slightly as the $\sigma_{\mathrm{v}}$, becomes higher. The $D$ shows minor increased when increasing of the $f$, OCRs and $\sigma_{\mathrm{v}}$, when subjected to increasing axial strain. Thus, input of parameter $\mathrm{G}$ and $\mathrm{D}$ can be review as technical values to key design structure on top of soil layer.
\end{abstract}

\section{Introduction}

The soils are often vulnerable to undrained cyclic loadings such as earthquakes, wind, wave loading and many more. These cyclic loadings have a wide range of amplitude, frequency, and duration. Similarly, response of soils to cyclic loading also varies widely and depends on various factors. Therefore, cyclic behaviour of clay is a matter of interest in geotechnical engineering practice and has been studied extensively, [15]. Present, development of city has become a major critical impact in Batu Pahat because of the development and modernisation. The problem occurred during post construction is the high settlement rate,

\footnotetext{
* Corresponding author: alvin@uthm.edu.my
} 
which reduce the strength of workability and shortens the design life of structure. In addition, Soft Clay are well known for their low strength and high compressibility. Usually, due to sedimentary process on different environment, both physical and engineering properties of the clays (namely void ratio, water content, grain size distribution, compressibility, permeability and strength) show a significant variation. Furthermore, they exhibit high compressibility (including an important secondary consolidation), reduced strength, low permeability and compactness, and consequently low quality for construction, [4].

\section{Problem on soil due to cyclic loading}

The soil deposits in many geotechnical engineering projects undergo dynamic cyclic loadings during their design lifetime. These repeated loadings may be due to environmental factors, such as seismic activity and ocean storms, or human activities, such as passing traffic and vibrating machinery installed on a structure or site. Importantly, the soil response generated by these dynamic cyclic loadings is typically more complex than that considered when conducting static analyses, requiring engineers to investigate the dynamic behaviour of soils in the laboratory, as well as in the field. The dynamic loading which are shear modulus and damping ratio of soil are expressed as a function of cyclic stress - strain amplitude and depend on various parameters such as effective vertical consolidation stress, OCR/Stress history, loading frequency and etc. They was important parameter to analyses the soil failure behaviour under specific cyclic loading circumstances. Various researchers investigated dynamic loading in various soils and the influence of the above mentioned factors. The hysteresis loops can be considered in order to calculate the secant shear modulus, $\mathrm{G}$ and damping ratio, $\mathrm{D}$ from the slope and the total area of the loop respectively. [11], observed an increase in shear modulus values with loading frequency from tests on Leda clay but drop at $1.0 \mathrm{~Hz}$, so they are not significant. The shear modulus corresponding to each effective confining stress increases slightly as the confining stress becomes higher. The damping ratio decreases as confining stress increases. The shear modulus decreases with increasing loading frequency. Moreover, when the loading frequency increases the damping ratio increases, [15]. However, for greater strain levels, the dependency of D and $\mathrm{G}$ on the loading frequency becomes less clear; moreover, both the shape of cycle and the average shear stiffness evolve progressively with the number of cycles imposed, [19]. The site-specific ground response analysis was performed using the modulus reduction and damping curves established for the site and the results are compared to those obtained using conventional practice.

The 'SHAKE' type site response analysis is currently the most common means of estimating site specific response during an earthquake. The modulus reduction and damping curves are key input to such an analysis, in addition to the soil profile and ground motion stress time history. According to related studies, the over consolidation state is an important effect for soil liquefaction potential. If a soil mass has experienced stresses higher than its current state, it is an over consolidated soil (OCR $>1)$. Over consolidated soils, OC have fewer settlements due to external loadings as compared with normally consolidated soils, $\mathrm{NC}$, [15]. Moreover, normally consolidated soil specimens yield highest peak strength. The peak strength of specimens decreases with an increase in OCRs. As OCR increases, the initial tangent modulus of clean sand decreases due to the lower current effective consolidation stress and consequently, the soil specimens become weaker. However, the OCR seems to have negligible effect on the initial tangent modulus of soil specimens with clay fines content, [16].This paper aims to explain in creating remolded (BPSC) samples 
with different pre consolidation pressures, to study the dynamic shear modulus, $G$ and damping ratio, D of (RBPSC) under cyclic loading with different $f$, OCRs, $\sigma_{\mathrm{v}}{ }^{\prime}$ and $\sigma_{\mathrm{c}}{ }^{\prime}$ and to analyses the relationship between dynamic shear modulus and damping ratio of the remolded (BPSC) with different OCR values under cyclic loading.

\section{Materials for testing}

The sampling of Batu Pahat Soft Clay, (BPSC) was taken at Research Centre of Soft Soil Universiti Tun Hussein Onn Malaysia, (RECESS UTHM) at depth of 1.5 meter using backhoe. Table 1 below shows the geotechnical properties of BPSC. The sample conducting the geotechnical properties was disturbed sample.

Table 1. Batu Pahat Soft clay soil characteristics

\begin{tabular}{|c|c|}
\hline \multicolumn{2}{|c|}{ Soil Characteristic - Batu Pahat Soft Clay (RECESS) } \\
\hline Liquid Limit, (\%) & 69.00 \\
\hline Plastic limit, (\%) & 34.46 \\
\hline Plastic Index, (\%) & 34.54 \\
\hline Natural moisture content, $(\%)$ & 87 \\
\hline Dry unit weight, $\gamma \mathrm{d},\left(\mathrm{kN} / \mathrm{m}^{3}\right)$ & 10.28 \\
\hline Specific Gravity & 2.700 \\
\hline Particles (\%) & 10.2 clay, 80.1 silt, 9 sand and 0.7 gravel \\
\hline
\end{tabular}

\section{Test equipment and procedures}

Method use for pre consolidation preparing remolded sample is using large strain consolidation apparatus. First the sample is dry in the oven over 1 day period and grinder into smaller size particles using crusher machine. Then, the sample of Batu Pahat Soft Clay, BPSC is mix with certain amount of water until it's become slurry using mixer machine and pour into cylinder mould diameter of $12.2 \mathrm{~cm}$ and being applied load of 50, 80 and 100 kpa on top. After 2 to 3 weeks consolidated, the samples are extrude out from the cylinder mould using pvc pipe size of $100 \times 50 \mathrm{~mm}$ using machinery extruder and wrap with plastic wrapper to avoid loss of moisture content and stored into plastic container under room temperature shows in Fig. 1.
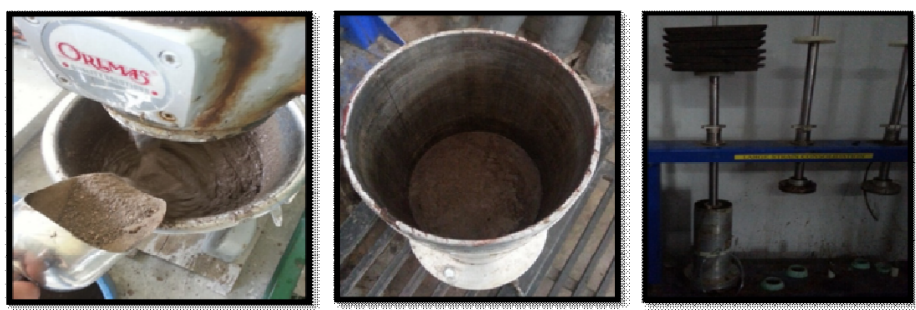

Fig. 1. Process of preparing sample

The pre - consolidation stress of 50,80 and $100 \mathrm{kpa}$ are chosen which are low, medium and high value because to represent different depth of sampling at the field but the samples conducting in laboratory method. The maximum load can be applied using large strain consolidation is $100 \mathrm{kpa}$. On top of that, the standard for dynamic cyclic triaxial test will follow ASTM D3999-11 for load control method and BS 1377 - 8: 1990 for Saturation, B - 
check and Consolidation Stages. In this research, the frequency selected are $0.1 \mathrm{~Hz}$ (wave action), $0.5 \mathrm{~Hz}$ (wind action) and $1 \mathrm{~Hz}$ (earthquake). The total number of samples are 27 will be tested using GDS Enterprise Level Dynamic Triaxial Testing System (ELDYN) show in Fig. 2 and Table 2.
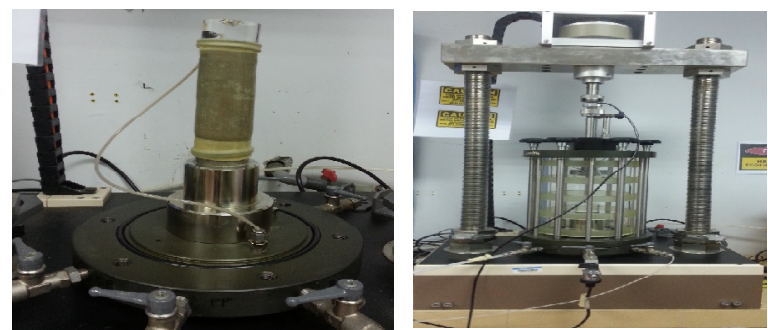

Fig. 2. GDS Enterprise Level Dynamic Triaxial Testing System (ELDYN)

Table 2. Total number of samples

\begin{tabular}{|c|c|c|c|c|c|c|c|c|}
\hline $\begin{array}{c}\sigma c^{\prime} \\
(\mathrm{kpa})\end{array}$ & $\begin{array}{c}\text { Load } \\
(\mathrm{kg})\end{array}$ & $\begin{array}{c}\sigma \mathrm{v}^{\prime} \\
(\mathrm{kpa})\end{array}$ & $\begin{array}{c}\text { Depth } \\
(\mathrm{m})\end{array}$ & $\begin{array}{c}\text { OCR } \\
\text { value }\end{array}$ & $\begin{array}{c}\text { OCR } \\
\text { status }\end{array}$ & $\begin{array}{c}\mathrm{f}(\mathrm{Hz}) \\
\text { No. } \\
\text { of } \\
\text { cycles }\end{array}$ & $\begin{array}{c}\text { No. of } \\
\text { samples }\end{array}$ \\
\hline 50 & 60 & 13 & 1.187 & 3.85 & OC & $0.1,0.5,1$ & 100 & 3 \\
\hline & & 25 & 1.811 & 2 & OC & $0.1,0.5,1$ & 100 & 3 \\
\hline & & 50 & 3.112 & 1 & NC & $0.1,0.5,1$ & 100 & 3 \\
\hline 80 & 95 & 20 & 1.551 & 4 & OC & $0.1,0.5,1$ & 100 & 3 \\
\hline & & 40 & 2.592 & 2 & OC & $0.1,0.5,1$ & 100 & 3 \\
\hline & & 80 & 4.673 & 1 & NC & $0.1,0.5,1$ & 100 & 3 \\
\hline 100 & 120 & 25 & 1.811 & 4 & OC & $0.1,0.5,1$ & 100 & 3 \\
\hline & & 50 & 3.112 & 2 & OC & $0.1,0.5,1$ & 100 & 3 \\
\hline & & 100 & 5.713 & 1 & NC & $0.1,0.5,1$ & 100 & 3 \\
\hline
\end{tabular}

\section{Results}

\subsection{Effect of loading frequency on shear modulus and damping ratio}

The Fig. 3 and 4 show the relationships between the shear modulus and the damping ratio with axial strain due to subjected loading frequencies of $0.1 \mathrm{~Hz}, 0.5 \mathrm{~Hz}$ and $1.0 \mathrm{~Hz}$. It can also be seen in Fig. 1 that at given loading frequency, shear modulus decreases with increasing axial strain and loading frequency. The shear modulus of $0.1 \mathrm{~Hz}$ start from $79.141 \mathrm{kpa}$ down to $10.011 \mathrm{kpa}$ whereas $0.5 \mathrm{~Hz}$ start from $96.541 \mathrm{kpa}$ down to $9.011 \mathrm{kpa}$ and $1.0 \mathrm{~Hz}$ start from $97.777 \mathrm{kpa}$ down to $8.012 \mathrm{kpa}$ which is the lowest value recorded in situation one. Meanwhile Fig. 2 shows that the damping ratio increases with increasing axial strain and loading frequency. The peak damping ratio of $0.1 \mathrm{~Hz}$ is 0.116 (lowest), 0.5 $\mathrm{Hz}$ is 0.121 (second highest) and $1.0 \mathrm{~Hz}$ is 0.131 (highest) in situation two. This trend was similar as Thammathiwat. A, and Chim - oye. W, 2006, whom found that the shear modulus decreased when loading frequencies increased while the damping ratio increased when loading frequencies increased undergone increasing in axial strain, [14]. This happen because frequency is the number of occurrences of a repeating event per unit time or cycle per time which is, in this research all the samples undergo 100 cycle of dynamic cyclic 
loading. The frequency loading of $0.1 \mathrm{~Hz}$ is noted as wave action which run 1000 seconds per cycle, $0.5 \mathrm{~Hz}$ is noted as wind action which run 200 seconds per cycle and $1.0 \mathrm{~Hz}$ is noted as earthquake action which run 100 seconds per cycle, hereafter simulated in the laboratory work using set of dynamic cyclic triaxial apparatus. This can be said that, the value of shear modulus and damping ratio are related on the loading frequency within period of time under specific number of cycle and vice versa or also can be said increase in loading frequency with time, more lower or higher value recorded in both situation. In real work at site, the value of shear modulus (stiffness) and damping ratio (decrease in the amplitude of an oscillation as a result of energy being drained from the system to overcome frictional or other resistive forces) can be used as technical value to construct structure above soil to withstand these prediction loading frequencies action.

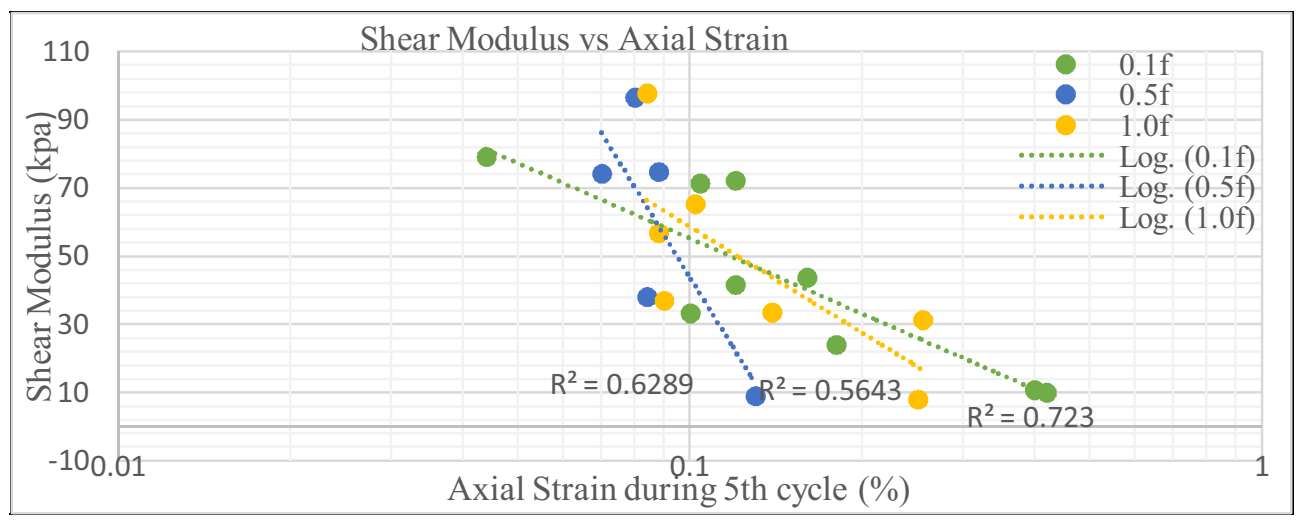

Fig. 3. Relationship between shear modulus and axial strain under different loading frequencies

\subsection{Effect of over - consolidation ratio, OCR on shear modulus and damping ratio}

The Fig. 5 and 6 show the relationships between the shear modulus and the damping ratio with axial strain due to subjected over - consolidation ratio, OCR of 1, 2, 3.85 and 4. It can also be seen in Fig. 3 that at given OCR, shear modulus decreases with increasing axial strain and Fig. 4 that at given OCR, damping ratio increases with increasing axial strain. Moreover, normally consolidated, $\mathrm{NC}=1$ shows the highest shear modulus value started from $97.777 \mathrm{kpa}$ down to $41.667 \mathrm{kpa}$, follow by over - consolidated, OC $=2$ which started from $74.747 \mathrm{kpa}$ and down to $24.073 \mathrm{kpa}, \mathrm{OC}=4$ which started from $69.767 \mathrm{kpa}$ down to $9.011 \mathrm{kpa}$ and $\mathrm{OC}=3.85$ shows the lowest value which started from $38.097 \mathrm{kpa}$ down to $8.012 \mathrm{kpa}$. This happen because in this research, $\mathrm{NC}=1$ has effective vertical stress of $\left(\sigma_{\mathrm{v}}{ }^{\prime}\right.$ $=50,80$ and $100 \mathrm{kpa}$ ) which $100 \mathrm{kpa}$ is the highest, while $\mathrm{OC}=2$ has effective vertical stress of $\left(\sigma_{\mathrm{v}}{ }^{\prime}=25,40\right.$ and $\left.50 \mathrm{kpa}\right)$ which $50 \mathrm{kpa}$ is the second highest, $\mathrm{OC}=4$ has effective vertical stress of $\left(\sigma_{\mathrm{v}}{ }^{\prime}=20\right.$ and $\left.25 \mathrm{kpa}\right)$ which $25 \mathrm{kpa}$ is the third highest and lastly $\mathrm{OC}=3.85$ has effective vertical stress of $\left(\sigma_{\mathrm{v}}^{\prime}=13 \mathrm{kpa}\right)$ which $13 \mathrm{kpa}$ is the lowest effective vertical stress.

This trend was similar with Thian [16], whom found that the stiffness of soil decreased when OCRs of soil was increased. The pre - consolidation stress, $\sigma^{\prime}{ }_{c}$ used in this research were $50 \mathrm{kpa}, 80 \mathrm{kpa}$ and $100 \mathrm{kpa}$. This result can be said that the NC is stiffer than OC but must referring to the effective vertical stress value. The consolidation is any process which involves a decrease in water content of saturated soil without replacement of water by air. 


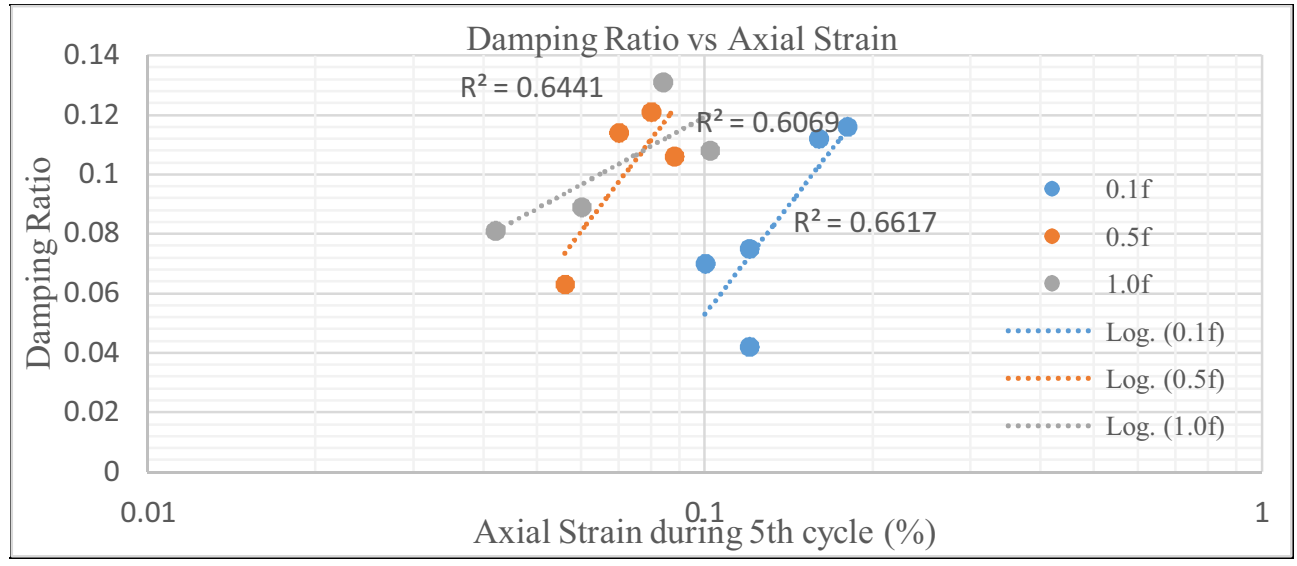

Fig. 4. Relationship between damping ratio and axial strain under different loading frequencies

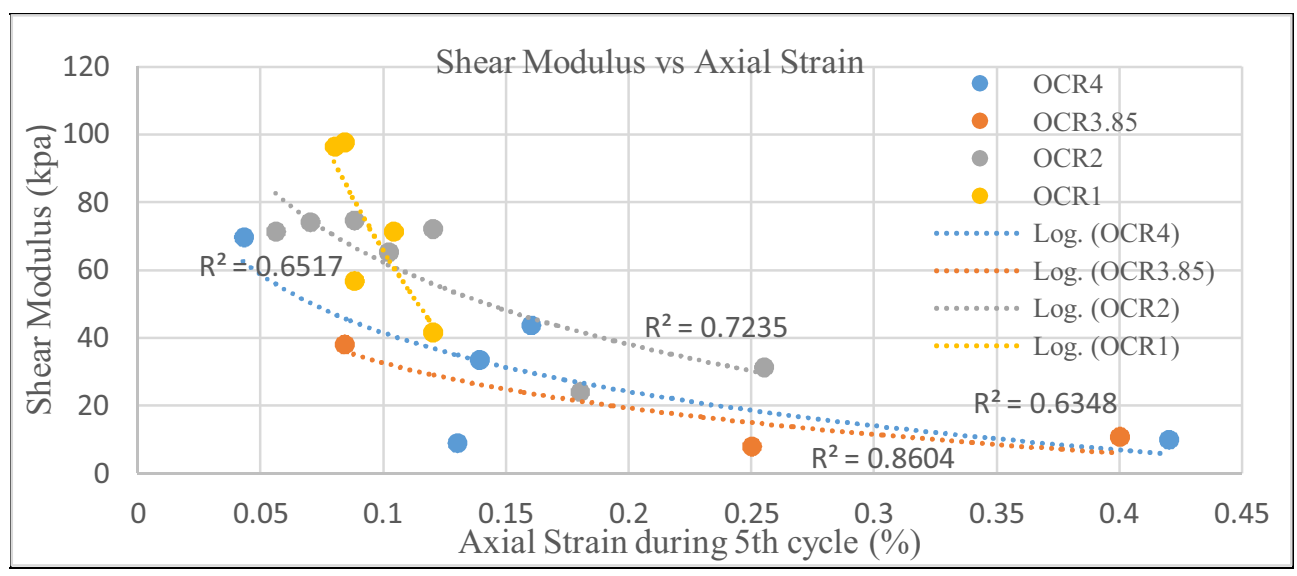

Fig. 5. Relationship between shear modulus and axial strain under different OCR

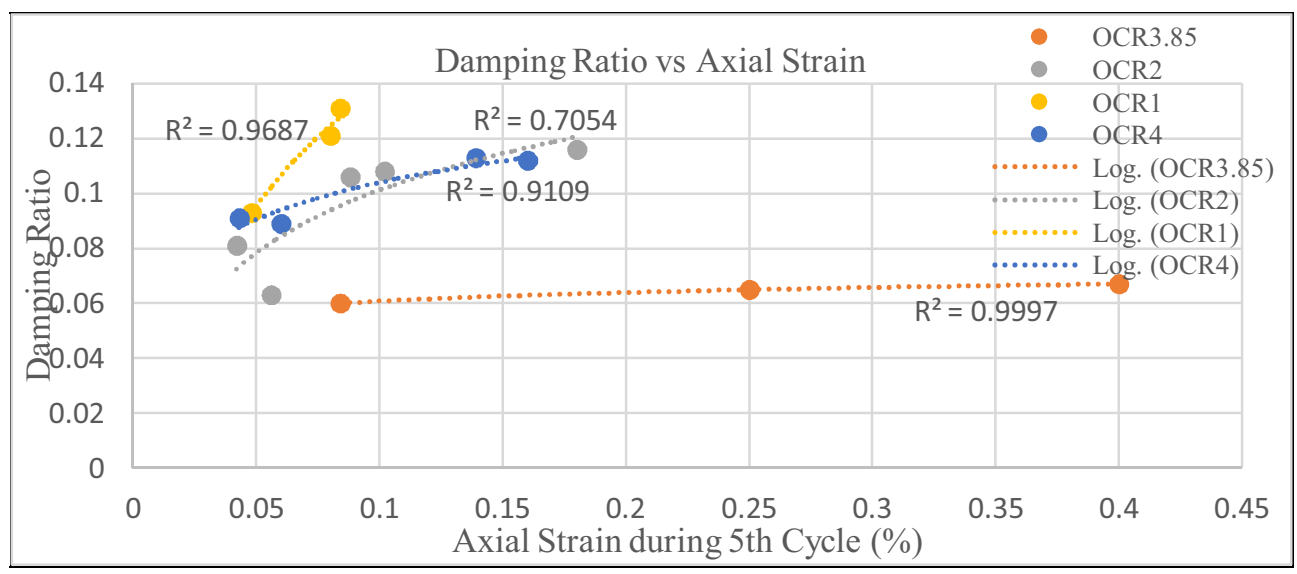

Fig. 6. Relationship between damping ratio and axial strain under different OCR 
When stress is removed from a consolidated soil, the soil will rebound, regaining some of the volume it had lost in the consolidation process whereas when stress reapplied, the soil will consolidate again. This happen may be due to geologic activity or human activity. The soil which had its load removed is considered to be over consolidated. The over consolidation ratio, OCR is defined as the highest stress experienced divided by the current stress. On the other hand, if the cohesive soil is over consolidated, there would be no significant settlement when a load is applied to the soil, [17]. Therefore, the significance and importance of OCR value can be used as technical parameter measurement indicator on the stress history and current stress applied on top of soil when construction take placed at real site condition.

\subsection{Effect of effective vertical consolidation stress/confining stress on shear modulus and damping ratio}

The Fig. 7 and 8 show the relationships between the shear modulus and the damping ratio with axial strain due to subjected effective vertical consolidation stress, $\left(\sigma_{v}{ }^{\prime}=13,20,25\right.$, $40,50,80$ and $100 \mathrm{kpa}$ ). It can also be seen in the Fig. 5 that at given $\sigma_{\mathrm{v}}^{\prime}$, shear modulus decreases with increasing axial strain and decreased in $\sigma_{v}{ }^{\prime}$ and the Figure 6 shows that at given $\sigma_{\mathrm{v}}{ }^{\prime}$, damping ratio increases with increasing axial strain and $\sigma_{\mathrm{v}}{ }^{\prime}$. Furthermore, at $\left(\sigma_{\mathrm{v}}{ }^{\prime}=\right.$ $13 \mathrm{kpa}$, the peak shear modulus, $G$ recorded was $38.097 \mathrm{kpa}$ which was lowest), at $\left(\sigma_{\mathrm{v}}{ }^{\prime}=20\right.$ $\mathrm{kpa}, \mathrm{G}=40.139 \mathrm{kpa})$, at $\left(\sigma_{\mathrm{v}}{ }^{\prime}=25 \mathrm{kpa}, \mathrm{G}=71.43 \mathrm{kpa}\right)$, at $\left(\sigma_{\mathrm{v}}{ }^{\prime}=40 \mathrm{kpa}, \mathrm{G}=74.231 \mathrm{kpa}\right)$, at $\left(\sigma_{\mathrm{v}}{ }^{\prime}=50 \mathrm{kpa}, \mathrm{G}=74.747 \mathrm{kpa}\right)$, at $\left(\sigma_{\mathrm{v}}{ }^{\prime}=80 \mathrm{kpa}, \mathrm{G}=79.141 \mathrm{kpa}\right)$ and $\left(\sigma_{\mathrm{v}}{ }^{\prime}=100 \mathrm{kpa}, \mathrm{G}=\right.$ 97.777 kpa which was highest).

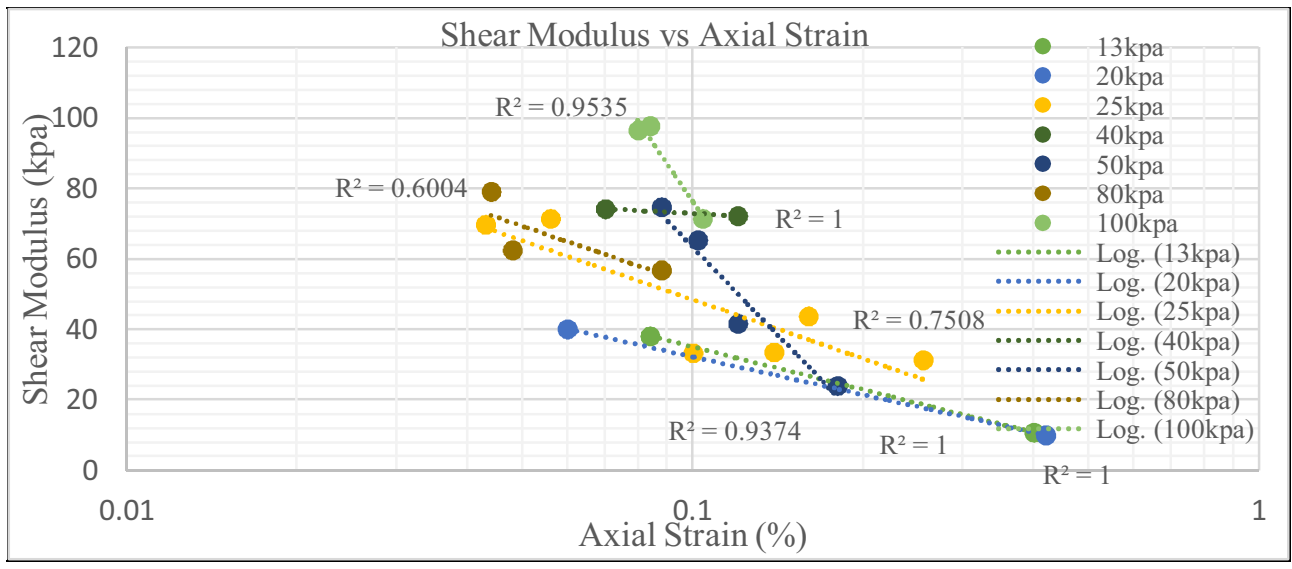

Fig. 7. Relationship between shear modulus and axial strain under different $\sigma_{v}{ }^{\prime}$

However, the differences between peak shear modulus and smallest value of each $\sigma_{v}{ }^{\prime}$ can't be taken as significant argument because each $\sigma_{\mathrm{v}}{ }^{\prime}$ had slightly differ reduction. In contra, the damping ratio, $\mathrm{D}$ at $\left(\sigma_{\mathrm{v}}{ }^{\prime}=13 \mathrm{kpa}\right.$, the peak $\mathrm{D}$ recorded was 0.067 which was lowest $)$, at $\left(\sigma_{\mathrm{v}}{ }^{\prime}=20 \mathrm{kpa}, \mathrm{D}=0.09\right)$, at $\left(\sigma_{\mathrm{v}}{ }^{\prime}=25 \mathrm{kpa}, \mathrm{D}=0.113\right)$, at $\left(\sigma_{\mathrm{v}}{ }^{\prime}=40 \mathrm{kpa}, \mathrm{D}=\right.$ $0.114)$, at $\left(\sigma_{\mathrm{v}}^{\prime}=50 \mathrm{kpa}, \mathrm{D}=0.116\right)$, at $\left(\sigma_{\mathrm{v}}{ }^{\prime}=80 \mathrm{kpa}, \mathrm{D}=0.121\right)$ and $\left(\sigma_{\mathrm{v}}^{\prime}=100 \mathrm{kpa}, \mathrm{D}=\right.$ 0.131 which was highest). This trend result was similar as previous journal, Thammathiwat. A, and Chim - oye. W, 2006, whom found that the shear modulus decreased when effective vertical consolidation stress increased while the damping ratio increased when effective vertical consolidation stress increased subjected to increasing in axial strain, [14]. Hence, it 
can conclude that the effective vertical stress, $\sigma_{\mathrm{v}}{ }^{\prime}$ value play high role in term of factors affecting the cyclic behaviour of soft clay under specific circumstances of cyclic loading. The shear modulus, $G$ and damping ratio, $D$ are not only needed for earthquake analysis but also for the design of machine foundations, wind power plant foundations, fast transportation systems, impacts and blast resistant structures and etc. [2].

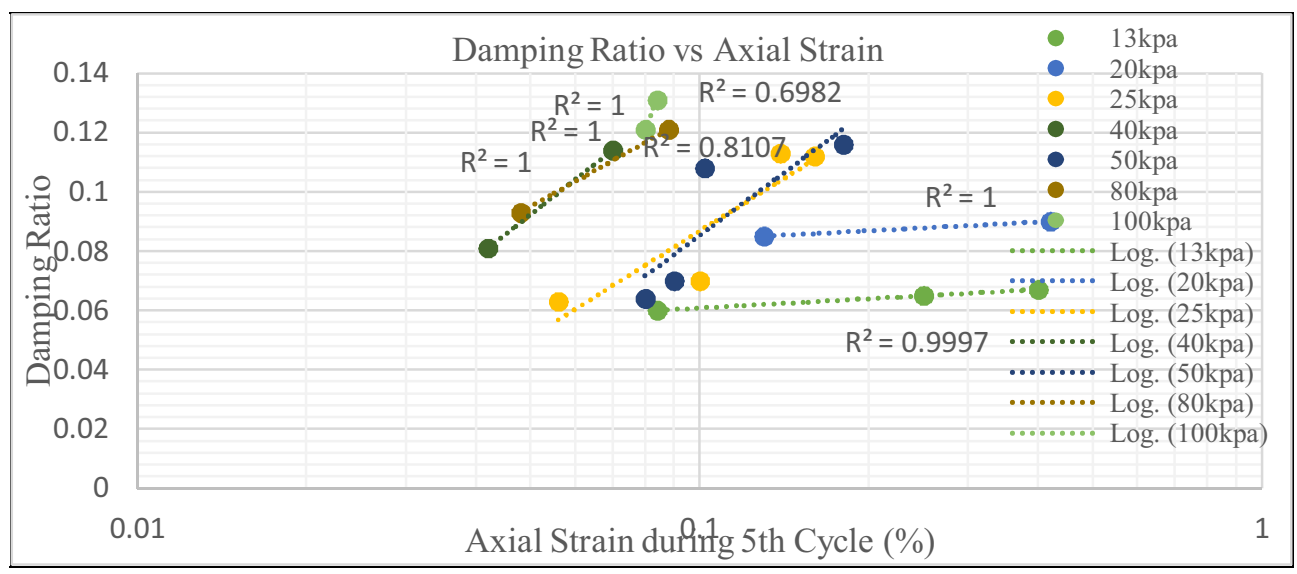

Fig. 8. Relationship between damping ratio and axial strain under different $\sigma_{\mathrm{v}}{ }^{\prime}$

\section{Conclusion}

From the results of dynamic cyclic triaxial tests to investigate the cyclic strength which were shear modulus and damping ratio of remolded Batu Pahat Soft Clay, BPSC, the following conclusions may be drawn:

i) The $100 \times 50 \mathrm{~mm}$ of remoulded samples are succeed simulated by using large strain consolidation apparatus of 50,80 and $100 \mathrm{kPa}$ of pre consolidation stress, contain moisture ranging within 42 to $55 \%$.

ii) The shear modulus decreased with increasing of axial strain for a given loading frequencies but damping ratio increased with increasing of loading frequencies and axial strain.

iii) The shear modulus corresponding to each effective vertical consolidation stress, $\sigma_{v^{\prime}}$ increases slightly as the $\sigma_{\mathrm{v}}$, becomes higher. The damping ratio increases as $\sigma_{v^{\prime}}$ increases.

iv) The peak strength of specimens decreases with an increase in OCRs but referring to its effective vertical consolidation stress respectively. Normally consolidated, $\mathrm{NC}$ of soil specimens yield highest peak strength compare to OC.

v) At given OCR, shear modulus decreases with increasing axial strain and at given OCR, damping ratio increases with increasing axial strain.

vi) The damping ratio increasing by slightly margin on increasing axial strain under specific loading frequencies, effective vertical consolidation stresses and OCRs.

\section{References}

[1] K.R. Devi, Cyclic triaxial tests on kolkata clay, Int. J. of Engineering Research and Technology, 2(7), 439-443, (2013) 
[2] N. Dibaji, W. Arghavan, Damping ratio of mixed gravel and clay, Int. of J. Science and Technology, 32(B5), 501-518, (2008)

[3] A. Erken, M.B.C. Ülker, The post cyclic shear strength of fine grained soils, 14th World Conference on Earthquake Engineering, Beijing, (2008)

[4] M.H. Ho, C.M. Chan, Some mechanical properties of cement Stabilized Malaysian Soft Clay, Int. J. of Civil, Environmental, Structural, Construction and Architectural Engineering, 5(2), $76-83$, (2011)

[5] L. Hu, J. Ding, Mechanical behavior of marine clay under wave loading, International J. of Offshore and Polar Engineering, 20(1), 5381, (2010)

[6] Y. Hu, H. Kempfert, Some important aspects in evaluating cyclic triaxial test on clayey soil, 14th Southeast Asian Geotechnical Conference, Hong Kong, (2001)

[7] M. Jiang, Stiffness degradation of soft marine clay under uniaxial cyclic loading, European J. Geotechnical Engineering, 17, 887 - 3895, (2012)

[8] H.M. Mohamad, Post-cyclic behaviour of soil - A critical review, 8th Malaysian Technical Universities Conf. on Engineering and Technology, Melaka, (2014)

[9] J. Ni, B. Indraratna, X.Y. Geng, C. Rujikiatkamjorn, The effect of the strain rate on soft soil behaviour under cyclic loading, 11th Australia - New Zealand Conf. on Geomechanics: Ground Engineering in a Changing World, Melbourne, (2012)

[10]C. Pasten, H. Shin, J.C. Santamarina, Long-term foundation response to repetitive loading, J. of Geotechnical and Geoenvironmental Engineering, 04013036, 1-11, (2013)

[11]K.K. Rasmussen, An Investigation of Monotonic and Cyclic Behaviour of Leda Clay, Master Thesis, University of Western Ontario, Canada, (2012)

[12]M. Shahin, R. Loh, H. Nikraz, Some observations on the behavior of soft clay under undrained cyclic loading, J. of Geo Engineering, 6(2), 109 - 112, (2011)

[13]H. Soltani-Jigheh, A. Soroush, Cyclic behavior of mixed clayey soils, Int. J. of Civil Engineering, 8(2), 99-106, (2010)

[14]A. Thammathiwat, W. Chim-Oye, Behavior of strength and pore pressure of soft bangkok clay under cyclic loading stress, Int. J. on the Biology of Stress, 9(4), 21- 28, (2004)

[15]T. Theenathayarl, Behaviour of sensitive leda clay under simple shear loading. Master Thesis, University of Peradeniya, Peradeniya, Sri Lanka, (2015)

[16]S.Y. Thian, Stress history effect on mining sand with fines contents, Int. Journal of Geomatics and Geoscience, 2(1), 1- 10, (2011)

[17]S.Y. Thian, C.Y. Lee, Effect of OCR on cyclic shear strength degradation of marine clay, Int. J. of Civil and Structural Engineering Research, 4(1), 280- 285, (2016)

[18]P. Tsai, N. Ni, Effects of types of additives on dynamic properties of cement stabilized soils, Int. J. of Applied Science and Engineering, 10(2), 131-144, (2012)

[19]C. Zambelli, A. D'onofrio, F.S.D. Magistris, Dependency of the mechanical behaviour of granular soils on loading frequency: Experimental results and constitutive modelling, Soil Stress Strain Behaviour Measurement Modeling and Analysis Geotechnical Symposium Proc., Rome, (2006) 